Moesker, M., Damen, N., Volmeijer, E., Dreesens, D., Loos, E.M. de, Vink, R., Coppens, M., Krujp, M.J., Meijer, K., Langelaan, M., Bruijne, M.C. de, Wagner, C. Guidelines' risk assessment recommendations for venous thromboembolism prophylaxis: a comparison and implementability appraisal. Thrombosis Research: 2018, 168(8), 5-13

\begin{tabular}{|l|l|}
\hline Postprint Version & 1.0 \\
\hline Journal website & https://linkinghub.elsevier.com/retrieve/pii/S0049-3848(18)30369-4 \\
\hline Pubmed link & https://www.ncbi.nlm.nih.gov/pubmed/29864630 \\
\hline DOI & $10.1016 /$ j.thromres.2018.05.028
\end{tabular}

This is a NIVEL certified Post Print, more info at http://www.nivel.eu

\title{
Guidelines' risk assessment recommendations for venous thromboembolism prophylaxis: A comparison and implementability appraisal
}

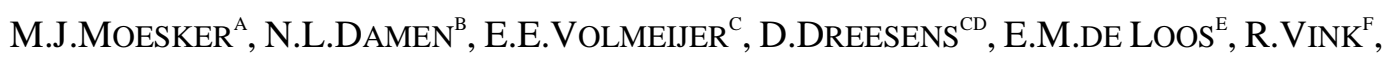
M.COPPENS ${ }^{\mathrm{G}}$, M.J.KRUIP ${ }^{\mathrm{H}}$, K.MEIJER ${ }^{\mathrm{I}}$, M.LANGELAAN ${ }^{\mathrm{B}}$, M.C.DE BRUIJNE ${ }^{\mathrm{A}}$, C.WAGNER ${ }^{\mathrm{AB}}$

\section{HighLIGHTS}

- Implementation of VTE prophylaxis guidelines for non-surgical patients is known to be suboptimal.

- We compared VTE prophylaxis risk assessment recommendations and appraised their implementability characteristics.

- We found differences in risk assessment recommendations, especially within bleeding risk assessment.

- We found implementation barriers concerning bleeding risk, mechanical prophylaxis and critical care patients.

- The implementation barriers should be taken into account when revising VTE prophylaxis guidelines.

\begin{abstract}
Introduction: Venous thromboembolism (VTE) prophylaxis guidelines for nonsurgical patients recommend VTE- and bleeding risk assessment to guide prophylactic strategies. These recommendations differ between guidelines and implementation is suboptimal. Assessing a guideline's implementability characteristics helps predicting the ease of implementation and reveals barriers.

Objectives: We aimed to compare guidelines' risk assessment recommendations and critically appraise the implementability characteristics.

Material and methods: Two guidelines, one from the American College of Chest Physicians and one from the National Institute for Health and Care Excellence were selected for comparison. Risk assessment methods and subsequent prophylactic recommendations were compared. Eight experts then appraised the guideline recommendations on intrinsic implementability characteristics using the GuideLine Implementability Appraisal (GLIA) instrument. GLIA identifies barriers and facilitators for guideline implementation in nine dimensions.

Results: Eleven out of 20 individual VTE-risk factors and 2 out of 19 individual bleeding-risk factors used, were present in both guidelines. Additionally, a high VTE- or bleeding risk was defined differently between the two guidelines. The GLIA appraisal identified implementation barriers within all recommendations
\end{abstract}


Moesker, M., Damen, N., Volmeijer, E., Dreesens, D., Loos, E.M. de, Vink, R., Coppens, M., Krujps M.J., Meijer, K., Langelaan, M., Bruijne, M.C. de, Wagner, C. Guidelines' risk assessment recommendations for venous thromboembolism prophylaxis: a comparison and implementability appraisal. Thrombosis Research: 2018, 168(8), 5-13

analyzed. On content level, barriers were identified in recommendations addressing bleeding risk assessment, mechanical prophylaxis and critical care patients. On implementability level, barriers were identified in decidability, flexibility, effect on process of care and computability dimensions.

Conclusion: Depending on the guideline used, VTE-prophylaxis will most likely be provided to different non-surgical patient populations, primarily due to discordance in bleeding risk assessment. Revising the recommendations, taking into account the most apparent implementation barriers, should be considered. However, insufficient evidence to support the recommendations currently complicates this.

$\begin{array}{ll}\text { ABBREVIATIONS } \\ \text { VTE } & \text { venous thromboembolism } \\ \text { ACCP } & \text { American College of Chest Physicians } \\ \text { NICE } & \text { National Institute for Health and Care Excellence } \\ \text { GLIA } & \text { Guideline Implementability Appraisal } \\ \text { ICU } & \text { intensive care unit } \\ \text { CCU } & \text { cardiac care unit } \\ \text { CVC } & \text { central venous catheter } \\ \text { RAM } & \text { risk assessment model } \\ \text { LMWH } & \text { low molecular weight heparin } \\ \text { LDUH } & \text { low dose unfractionated heparin } \\ \text { GCS } & \text { graduated compression stockings } \\ \text { IPC } & \text { intermittent pneumatic compression }\end{array}$

\section{INTRODUCTION}

Venous thromboembolism (VTE), comprising deep vein thrombosis and pulmonary embolism, is a well-known complication in hospitalized patients, resulting in a significant increase in patient mortality and morbidity [1,2]. Half to three quarters of all hospital-associated VTE events occur in non-surgical patients $[3,4]$.

Pharmacological prophylaxis with low molecular weight heparin reduces the incidence of VTE in hospitalized non-surgical patients [[5], [6], [7]]. The use of VTE-prophylaxis is supported by evidence based consensus guidelines available since 1986 [8,9]. These guidelines present ways to support risk assessment of VTE based on numerous risk factors. Patients classified with a high risk for VTE are eligible for prophylaxis. However, multiple guidelines are available for the same clinical problem which leads to guidelines conflicting with each other. As a result guidelines validity is questioned and the clinical decision making is complicated [10]. Few studies addressed this issue for VTE-prophylaxis guidelines. The studies that did, were mainly aimed at surgical patient populations [[11], [12], [13]]. Furthermore, the implementation of VTE-prophylaxis guidelines in hospitalized nonsurgical patients is known to be suboptimal with reported adherence rates ranging from $12.7 \%$ to $49 \%$ [[14], [15], [16], [17]]. Interventions aimed at improving guideline adherence resulted in improvements averaging around 80\% [18]. However, a majority of these interventions require substantial resources to maintain high guideline adherence. Until now, the implementability of VTE guidelines for nonsurgical patients has hardly been studied. 
Moesker, M., Damen, N., Volmeijer, E., Dreesens, D., Loos, E.M. de, Vink, R., Coppens, M., Krujp M.J., Meijer, K., Langelaan, M., Bruijne, M.C. de, Wagner, C. Guidelines' risk assessment recommendations for venous thromboembolism prophylaxis: a comparison and implementability appraisal. Thrombosis Research: 2018, 168(8), 5-13

The implementability of a guideline can be defined as "a set of characteristics that predict the relative ease of implementation of guideline recommendations" [19]. Implementability factors can be categorized as extrinsic or intrinsic. Extrinsic factors can be organizational and provider specific obstacles inherent to a specific healthcare system [19]. Intrinsic characteristics are for example: unambiguity, consistency, and completeness [20,21]. Identification of these intrinsic factors is especially important because they can, in a majority of cases, be taken care of during the guideline development [19]. Consequently, if improvements are made to these intrinsic characteristics, this could result in improved evidence-based care and outcomes [22]. To our knowledge the implementability of guidelines addressing VTE-prophylaxis for hospitalized non-surgical patients has not been assessed before. Therefore, our aim for this study is twofold.

First, to compare the risk assessment recommendations of two influential international guidelines for VTE-prophylaxis in hospitalized non-surgical patients. Second, to critically appraise the two guidelines on the intrinsic implementability characteristics of their risk assessment recommendations. As a result, inconsistencies between guideline recommendations and possible barriers and facilitators for the guideline implementability will be revealed.

\section{MATERIAL AND METHODS}

\subsection{Patient population and guideline selection}

This study focuses on non-surgical patients admitted for an acute medical illness. Patients admitted for stroke are outside the study scope, since specific recommendations for VTE-prophylaxis for this group exist.

We aimed to compare two influential original guidelines that were independently developed and not adaptations from other guidelines. Expert opinion was used to determine the most important original guidelines. In preparation of a Dutch VTEprophylaxis guideline, experts from the 'Knowledge Institute of Medical Specialists' (Kennisinstituut van Medisch Specialisten) Utrecht, The Netherlands designated two original guidelines as most influential. These were "the antithrombotic therapy and prevention of thrombosis, 9th edition" guideline from the American College of Chest Physicians (ACCP) published in 2012 and the "venous thromboembolism in adults admitted to hospital: reducing the risk" guideline from the National Institute for Health and Care Excellence (NICE) published in 2010 [23,24]. Both served as a basis for the Dutch guideline concerning V-prophylaxis [25].

\subsection{Aim 1: comparison of risk assessment recommendations}

The recommendations on the use of VTE-prophylaxis typically require a trade-off between patient's VTE- and bleeding risk. When the VTE-risk is elevated, VTEprophylaxis should be considered. However, if the patient's bleeding risk is also elevated, pharmacologic prophylaxis can be contra-indicated, because of its increased risk for bleeding complications. Mechanical forms of VTE-prophylaxis might be more suitable for these patients. Recommendations from both guidelines addressing the following risk assessment components were selected for a comparison on content level:
1.
Risk factors included in the VTE-risk assessment
2.
Risk factors included in the bleeding risk assessment
3.
Criteria for indicating pharmacologic VTE-prophylaxis 
Moesker, M., Damen, N., Volmeijer, E., Dreesens, D., Loos, E.M. de, Vink, R., Coppens, M., Krujps M.J., Meijer, K., Langelaan, M., Bruijne, M.C. de, Wagner, C. Guidelines' risk assessment recommendations for venous thromboembolism prophylaxis: a comparison and implementability appraisal. Thrombosis Research: 2018, 168(8), 5-13

4.

Criteria for contra-indicating VTE-prophylaxis

5.

Criteria for indicating mechanical VTE-prophylaxis

\subsection{Aim 2: implementability appraisal}

The second aim of this study was to critically appraise the included guideline recommendations on their intrinsic implementability characteristics using a panel of experts. The Guideline Implementability Appraisal (GLIA) instrument was used for this [19]. This instrument collects expert opinion using structured questions to anticipate on guideline implementation barriers. GLIA consists of two parts. The first part includes nine questions on global considerations to be answered for the guideline as a whole. The second part includes 21 questions specifically aimed at the individual guideline recommendations and, as such, must be answered for each individual recommendation. The 21 questions in part two cover eight dimensions relating to intrinsic implementability: executability, decidability, validity, flexibility, effect on process of care, measurability, novelty/innovation and computability. The GLIA instrument is provided in supporting information Table 1. All questions have four response categories: 'yes', 'no', 'not applicable' and 'unsure'. Questions answered with ' $n o$ ' indicate implementability barriers. Part two of the GLIA instrument, was only applied to recommendations concerning risk assessment and prophylaxis use. The recommendations selected for GLIA appraisal are given in Table 1. When a recommendation referred to other specific information in the guideline, e.g. a table, this information was provided together with the recommendation to the appraisal panel.

\section{[TABLE 1]}

The appraisal was done using the 'eGLIA' electronic version of the GLIA instrument, available at http://nutmeg.med.yale.edu/eglia/ .

\subsubsection{Appraisal process}

Our eGLIA appraisal panel comprised four clinical experts in the field of thrombosis and four guideline implementation experts, as was recommended previously [19]. Five of these experts were also involved in the development and implementation of the Dutch Antithrombotic Policy guideline [26]. All appraisers independently completed the appraisal for the selected recommendations and global dimensions. In accordance with previous studies, after finishing the appraisal, each panel member received an overview of their own and other panel members' answers [27]. eGLIA questions for which discrepancy in appraisal existed, defined as less than five appraisals in any of the response categories 'yes', 'no' or 'not applicable', were identified for discussion with the panel. Six appraisers attended a teleconference where discrepancies were discussed. The remaining two appraisers commented by email on the discussion results. Due to the amount of questions for which discrepancy existed, an extensive discussion for every eGLIA question was not feasible. Therefore, only the most important dimensions for guideline implementability, i.e. the executability and decidability dimension, were discussed by phone. If a recommendation is not able to clearly communicate what to do (executability) or when to do it (decidability) it is not fully implementable [19]. Additionally the global considerations were discussed in detail. Discrepancy in the remaining dimensions was discussed by structured emails. 
Moesker, M., Damen, N., Volmeijer, E., Dreesens, D., Loos, E.M. de, Vink, R., Coppens, M., Krujp, M.J., Meijer, K., Langelaan, M., Bruijne, M.C. de, Wagner, C. Guidelines' risk assessment recommendations for venous thromboembolism prophylaxis: a comparison and implementability appraisal. Thrombosis Research: 2018, 168(8), 5-13

\subsubsection{Analysis}

A priori we defined that the occurrence of at least five 'no' appraisals for a single eGLIA question results in a classification as barrier to guideline implementation for that question. Correspondingly, the occurrence of at least five 'yes' appraisals was defined as a facilitator. If after the discussion, agreement could still not be reached the eGLIA question was marked as a borderline barrier showing the tendency towards the most prevalent response. The proportions of identified barriers per guideline were calculated to enable a comparison between both guidelines on their intrinsic implementability characteristics.

\section{RESULTS}

\subsection{Comparison of risk assessment recommendations}

Table 2 lists the risk assessment components for VTE-prophylaxis together with the guideline's content and recommendations in relation to these components. In the table, seemingly similar risk factors used in the two guidelines are displayed next to each other.

\section{[TABLE 2]}

\subsubsection{Risk factors included in the VTE-risk assessment}

Combined, 20 individual VTE-risk factors are listed in the guidelines. Eleven are prevalent in both guidelines with operational differences between the guidelines for: 'age' ( $\geq 60 \mathrm{vs} \geq 70$ years), 'cardiac function' (heart failure or myocardial infarction only vs heart diseases in general), 'respiratory function' (respiratory failure vs respiratory pathologies) and 'mobility impairments' (reduced mobility $\geq 3$ days vs reduced mobility $\geq 3$ days or reduced mobility relative to normal state). ACCP reports an additional three VTE-risk factors not found in NICE. Whereas, NICE reports an additional six risk factors.

\subsubsection{Risk factors included in the bleeding risk assessment}

Combined, 19 individual bleeding risk factors are listed in the guidelines. Two of which are prevalent in both: 'active bleeding' and a 'low platelet count/thrombocytopenia'. The threshold value for thrombocytopenia differs between ACCP $\left(<50 \times 10^{9} / \mathrm{L}\right)$ and NICE $\left(<75 \times 10^{9} / \mathrm{L}\right)$. ACCP reports ten additional bleeding risk factors of which, 'age', 'ICU/CCU admission', 'central venous catheter', 'rheumatic disease' and 'current cancer' are concomitantly used as VTE-risk factors in ACCP or NICE. NICE reports seven additional bleeding risk factors, of which 'acute stroke' is a VTE-risk factor in ACCP.

\subsubsection{Criteria for indicating pharmacologic VTE-prophylaxis}

Recommendations on when pharmacologic prophylaxis is recommended differ between ACCP and NICE. ACCP adopted the PADUA-score and recommends pharmacologic prophylaxis for patients with a score of at least 4 [28]. 'Active cancer', 'previous VTE', 'reduced mobility' and 'thrombophilic conditions' score 3 points. Following NICE's recommendations, mobility impairments must be present in order to justify the use of pharmacologic prophylaxis. Furthermore, NICE has a separate recommendation for cancer patients, recommending pharmacologic 
Moesker, M., Damen, N., Volmeijer, E., Dreesens, D., Loos, E.M. de, Vink, R., Coppens, M., Krujp M.J., Meijer, K., Langelaan, M., Bruijne, M.C. de, Wagner, C. Guidelines' risk assessment recommendations for venous thromboembolism prophylaxis: a comparison and implementability appraisal. Thrombosis Research: 2018, 168(8), 5-13

prophylaxis if one or more other VTE-risk factors are present. This emphasis on mobility impairments and cancer is shared with ACCP's recommendations since these risk factors correspond with 3 PADUA points, requiring only 1 more to reach the threshold value for VTE-prophylaxis.

Both guidelines also recommend the use of prophylaxis in critically ill patients (NICE) or patients admitted to the ICU or CCU (ACCP). Lastly, NICE has a separate recommendation for patients with a central venous catheter (CVC).

\subsubsection{Criteria for contra-indicating VTE-prophylaxis}

ACCP's risk factors for bleeding are adopted from the IMPROVE study that identified risk factors at admission associated with in-hospital bleeding [29]. ACCP contra-indicates pharmacologic prophylaxis if any of the risk factors 'active gastroduodenal ulcer', 'bleeding in three months before admission', and 'platelet count below $50 \times 10^{\circ} / L^{\prime}$ are present. Additionally, pharmacologic prophylaxis is contra-indicated with the presence of two or more bleeding risk factors or if the patient is actively bleeding. NICE contra-indicates pharmacologic prophylaxis if any of the listed risk factors are present, unless the VTE-risk outweighs the risk of bleeding. No recommendation is given on how to proceed with this trade-off between VTE- and bleeding risk.

\subsubsection{Criteria for indicating mechanical VTE-prophylaxis}

Both guidelines recommend mechanical forms of VTE-prophylaxis, such as graduated compression stockings or intermittent pneumatic compression, if pharmacologic VTE-prophylaxis is contra-indicated because of an increased risk for, or an active bleeding.

\subsection{Implementability appraisal of the guidelines}

Fig. 1 presents the final implementability appraisal results. For the ACCP-guideline, 33 implementation barriers, six borderline barriers and 84 implementation facilitators were identified. For the NICE-guideline, 51 implementation barriers and 144 implementation facilitators were identified. The proportion of implementation barriers within each guideline's total amount of appraised recommendations was 0.262 and 0.258 for ACCP and NICE respectively. All appraised recommendations for both guidelines contained at least one implementation barrier.

\section{[FIGURE 1]}

\subsubsection{Facilitators to guideline implementation}

Four dimensions were primarily appraised as facilitating the guideline's implementation. First, the executability dimension primarily contains clear descriptions of the recommended actions. However, "the optimal use of mechanical prophylaxis" found in the ACCP was too vague. Additionally, for both guidelines it is unclear when to provide critical patients with prophylaxis.

Second, the measurability dimensions consists solely of facilitators, meaning that adherence to, and outcomes of the recommended actions are measurable. Third, the novelty/innovation dimension was mostly facilitating implementation, indicating no new skills are required and recommendation are consistent with existing attitudes. Recommendations for mechanical prophylaxis are an exception to 
Moesker, M., Damen, N., Volmeijer, E., Dreesens, D., Loos, E.M. de, Vink, R., Coppens, M., Krujp, M.J., Meijer, K., Langelaan, M., Bruijne, M.C. de, Wagner, C. Guidelines' risk assessment recommendations for venous thromboembolism prophylaxis: a comparison and implementability appraisal. Thrombosis Research: 2018, 168(8), 5-13

this. Several appraisers argued that its use, requires knowledge and skills not readily available in current practice resulting in borderline barriers found in the ACCP's novelty/innovation domain.

Lastly, the validity dimension was appraised as facilitating for ACCP and to a lesser extent for NICE, mainly because the quality of the evidence that supports the recommendation is not explicitly stated in NICE's recommendations.

\subsubsection{Barriers to guideline implementation}

Barriers to guideline implementation were primarily present in four dimensions. First, decidability barriers were found in ACCP's recommendations addressing the bleeding risk assessment. A clear definition of patients at "high risk for bleeding" is lacking, preventing a consistent implementation. Furthermore, the definitions "critically ill" and "acutely ill" were deemed ambiguous definitions. NICE's decidability barriers occurred in recommendations addressing bleeding risk and critical patients. Vague terminology such as "reason of admission", "planned interventions" and "other therapies" were given as a reason. NICE's recommendation 1.4.6 through 1.4 .9 were partially overlapping with recommendation 1.1.2 because all can be applied to cancer patients. Internal consistency (global dimension question 7) was therefore appraised as a barrier. Second, the flexibility dimension was similarly appraised between the guidelines. Question 18: 'the individualization of the recommendations based on patient characteristics' was a barrier for several recommendations due to vague terminology for patient characteristics. Also question 19: 'modification of the recommendations based on practice characteristics' was a barrier for all recommendations in both guidelines.

Third, barriers in the effect on process of care dimension occurred in mechanical prophylaxis recommendations. The use of intermittent pneumatic compression was seen as a workflow disruption due to complexity, time consumption, monetary investments and requiring new skills. Borderline barriers emerged in ACCP's recommendations for VTE- and bleeding risk assessment. Together, information on more than 20 variables is required per patient. Some appraisers believed this disrupts current workflow.

Lastly, the computability dimension contained barriers for electronic implementation of the guidelines. Doubts were expressed on the electronic availability and specificity of all the required patient data for the risk assessments. A majority of the required patient data will only be available in open text fields, hindering the systematic use for risk assessments. Assuming this can be resolved, the recommended actions in both guidelines are specific enough for an electronic execution (questions 29,30). For example issuing an electronic order for prophylaxis.

\section{DISCUSSION}

The aim of this study was to compare the risk assessment recommendations for VTEprophylaxis in hospitalized non-surgical patients used in two influential international guidelines. Secondly, these recommendations were critically appraised by a panel of experts on their implementability characteristics. 
Moesker, M., Damen, N., Volmeijer, E., Dreesens, D., Loos, E.M. de, Vink, R., Coppens, M., Krujps M.J., Meijer, K., Langelaan, M., Bruijne, M.C. de, Wagner, C. Guidelines' risk assessment recommendations for venous thromboembolism prophylaxis: a comparison and implementability appraisal. Thrombosis Research: 2018, 168(8), 5-13

\subsection{Risk assessment comparison}

Concerning the identification of patients being at risk for VTE, ACCP and NICE largely correspond with each other. The individual risk factors required in the determination of VTE-risk largely overlap. Critical care admissions, reduced mobility and cancer presence are major components included in VTE risk. This is in agreement with existing literature, since these risk factors are prevalent in most other risk assessment models (RAMs) available for VTE [30,31]. In general however, VTE RAMs that have been externally validated, including the PADUA-score, show limited performance in guiding the use of VTE-prophylaxis for high risk patient groups [32].

Bleeding risk assessment differences are more apparent. Just two of the 19 individual bleeding risk factors occur in both the ACCP and NICE. Also, the threshold for contra-indicating pharmacologic prophylaxis differs. In the NICE recommendation, the presence of any of the bleeding risk factors contra-indicates pharmacologic prophylaxis. Whereas, in the ACCP only four of the listed risk factors are absolute contra-indications. This difference might be explained by the limited availability of evidence for bleeding risk assessment, resulting in different approaches within each guideline development group. Only recently the IMPROVE bleeding RAM was externally validated [33]. Approximately $20 \%$ of the patients were classified with high bleeding risk. The incidence of bleeding events in this high-risk group was over two-fold higher than in the low-risk group, but the overall performance of the model was poor.

Ideally a combined assessment of both VTE and bleeding risk should be performed prior to using prophylaxis. Interestingly, the ACCP lists three risk factors used in both VTE- and bleeding risk assessment: 'cancer', 'age' and 'ICU/CCU admission.' This suggests a positive relationship between the two risks, complicating the decision making. A recent evaluation of combined risk assessment concluded that the physicians' attitudes on prescribing prophylaxis was more influenced by VTE- than bleeding risk when evaluating patients with both high VTEand bleeding risk [34].

\subsection{Implementability of risk assessment recommendations}

The assessment of implementability of both guidelines showed that none of the appraised recommendations in any of the guidelines were straightforward to implement. In absence of validated means to quantify and compare guideline implementability between guidelines, we consider the 0.04 difference in proportions of identified barriers a non-significant difference. Nonetheless, the identified barriers and facilitators give us vital information in how guidelines are perceived in their current form and we will touch upon those now.

Clusters of barriers can be identified on recommendation and dimension level. On recommendation level, apparent implementation barriers occur for recommendations regarding mechanical prophylaxis, critical care patients and bleeding risk assessment. Use of mechanical prophylaxis in non-surgical patients is minimal and attitudes towards its use can differ between and within countries [14,35]. For example, mechanical prophylaxis in non-surgical patients is more common in the United States [36]. This might have influenced the panel's appraisal for mechanical prophylaxis. The bleeding risk assessment suffered from decidability barriers in both guidelines. ACCP's recommendation lacks a definition of high risk for bleeding and NICE's recommendation lacks a clear description of how to handle the trade-off between 
Moesker, M., Damen, N., Volmeijer, E., Dreesens, D., Loos, E.M. de, Vink, R., Coppens, M., Krujps M.J., Meijer, K., Langelaan, M., Bruijne, M.C. de, Wagner, C. Guidelines' risk assessment recommendations for venous thromboembolism prophylaxis: a comparison and implementability appraisal. Thrombosis Research: 2018, 168(8), 5-13

VTE- and bleeding risk if both are elevated. These barriers reflect the combined VTE- and bleeding risk assessment issue mentioned before and also the observed variation of the bleeding risk assessment content of the two guidelines.

Critical patients are addressed in separate recommendations. Besides a lacking definition for critical patients, the recommendations do not allow for individualization of the recommended actions based on patient characteristics. This contrasts with recommendations for non-critical patients in which numerous risk factors are involved. Additional ambiguous terminology used by the NICE for critical patients makes implementation of this recommendation uncontrollable. To overcome these executability and decidability barriers, the formulation of the recommendations should be modified to a structured, concise and more uniform way. The Institute of Medicine suggests that "a recommendation should be articulated in a standardized form detailing precisely what the recommended action is and under what circumstances it should be performed." [37] The implementability of both guidelines is likely to benefit from more explicit distinctions between the affected patient populations and accompanying risk assessment(s).

Several other clusters with barriers were found at the dimension level. First, NICE's recommendations lacked an explicit stating of the quality of the supporting evidence. Strong and supporting evidence was identified as an influencing feature promoting guideline use by others [38]. ACCP's use of the GRADE scheme for quality of the supporting evidence as well as the strength of the recommendation is a comprehensive way to provide this information to guideline users.

Next, flexibility barriers complicate modification of recommendations based on varying practice characteristics. These characteristics can be very divergent such as a lack of time or the unavailability of certain resources. Although these can be regarded as external factors, a flexible recommendation enables anticipation on such practice or 'real life' variations, increasing the intrinsic implementability of the recommendations and the guideline.

Furthermore, the computability dimension contained barriers. Electronic implementation of guidelines is gaining more and more attention. Various efforts regarding the risk assessment and correct use of VTE-prophylaxis have been made to improve the implementation of guidelines $[18,39,40]$. The main concerns we identified are insufficient patient information in the electronic health records and insufficient specificity of the risk factors for electronic use. Substantial alterations and additions are required in order to allow for electronic implementation of the recommendations. Significant monetary and resource investments are required to facilitate this. Electronic interventions however, are successful in improving guideline implementation and adherence $[18,39,40]$.

The implementability appraisal in this study should not be confused with an overall quality appraisal of guidelines. Appraisal instruments such as the AGREE II also cover many more guideline characteristics [41]. For example, stakeholder involvement or the thoroughness of guideline development. These characteristics are not explicitly involved in eGLIA but have been shown to be predictors of guideline implementation indicating a relation between a guideline's quality and implementability characteristics [42]. AGREE II however, does not solely focus on guideline implementability and hence, does not cover all implementability dimensions as extensively as eGLIA. Moreover, eGLIA assesses the guideline on 
Moesker, M., Damen, N., Volmeijer, E., Dreesens, D., Loos, E.M. de, Vink, R., Coppens, M., Krujp; M.J., Meijer, K., Langelaan, M., Bruijne, M.C. de, Wagner, C. Guidelines' risk assessment recommendations for venous thromboembolism prophylaxis: a comparison and implementability appraisal. Thrombosis Research: 2018, 168(8), 5-13

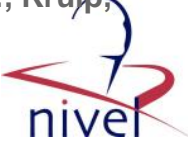

overall and individual recommendation level, whereas AGREE II assesses the guideline solely on an overall level. Our findings show that the guideline characteristics concerning implementability vary extensively on individual recommendation level underlining the relevance of recommendation level assessment. Consequently, guideline development groups can more accurately target their enhancements on recommendations most needing improvement. A combined assessment with eGLIA and AGREE II seems reasonable, but they are partly overlapping, resulting in duplicate assessment efforts [43]. Merging the two instruments can be beneficial.

\subsection{Clinical relevance}

Besides the relevance for implementation efforts, our findings are also relevant to VTE-prophylaxis risk assessment in clinical practice. Regarding the risk assessment differences, a heterogeneous deployment of VTE-prophylaxis in populations subject to the ACCP or NICE guidance can be expected. Especially the contra-indications for VTE-prophylaxis are perceived very differently. Whether this subsequently influences outcomes for individual patients is not directly known. However, several recent studies established associations between guideline adherence and patient outcomes. Lower adherence with VTE-prophylaxis guidelines was associated with increased mortality, longer length of stay and higher VTE incidence [[44], [45], [46]]. Since, by concept, adherence is based on guideline content, this is evidence for an association between guideline content and patient outcomes. Furthermore, the implementability differences we identified are also likely to influence the ease of implementation and hence the adherence of clinical practice to each of the guidelines. Possibly indirectly influencing patient outcomes.

\subsection{Limitations}

First of all, this study is limited to two international guidelines regarding VTEprophylaxis in non-surgical patients. Including a larger number of guidelines would have broadened our analysis and allowed the identification of certain key risk factors. Key risk factors are expected to be prevalent in most available guidelines whereas, more trivial risk factors will be restricted to a minority of guidelines. Comparisons on this scale however will be complicated by guidelines that are locally adapted versions of other, international, guidelines. For example the Australian and Canadian guidelines are both informed by ACCP guidelines. Given this, and our aim to complement our guideline comparison with the implementability appraisal requiring a significant time investment by appraisers, we limited ourselves to two influential original guidelines.

Second, the majority of the appraisal panel was unfamiliar with the appraisal of guidelines using the eGLIA instrument. By providing the panel with a manual for the appraisal with eGLIA and discussing the results afterwards, any misunderstandings could be resolved. Also, all panel members were experienced in guideline development and/or implementation and hence, were familiar with the constructs in eGLIA. Future applications of eGLIA are likely to benefit from a training session before appraisal commences. This might reduce the time necessary for the appraisal. Third, questions can be raised on the reliability of the eGLIA instrument. Similar recommendations between the two guidelines were appraised differently. E.g. within the novelty/innovation dimension, barriers occurred in ACCP's recommendations concerning mechanical prophylaxis whereas these were not identified in NICE's 
Moesker, M., Damen, N., Volmeijer, E., Dreesens, D., Loos, E.M. de, Vink, R., Coppens, M., Krujp, M.J., Meijer, K., Langelaan, M., Bruijne, M.C. de, Wagner, C. Guidelines' risk assessment recommendations for venous thromboembolism prophylaxis: a comparison and implementability appraisal. Thrombosis Research: 2018, 168(8), 5-13

seemingly similar recommendation. To our knowledge published results of any intraand inter-rater agreement reliability testing of the eGLIA instrument are not available, although plans for doing so were raised shortly after its development in 2005 [19]. Reliability testing, preferably on the dimension level, would allow eGLIA users to better frame any identified borderline barriers or other inconsistencies while interpreting the results.

Fourth, the appraisal panel solely consisted of Dutch experts appraising from a Dutch perspective, possibly limiting the generalizability to other healthcare settings.

\section{CONCLUSIONS}

We can conclude that depending on the guideline used VTE-prophylaxis will most likely be provided to different non-surgical patient populations. This variation is expected to occur more often because of discordance in bleeding- than in VTE-risk assessment. Difficulties in implementing the guidelines are expected specifically for recommendations concerning bleeding risk assessment, mechanical prophylaxis and critical care patients. Some other issues can arise while trying to implement the risk assessment recommendations electronically and implementing the guidelines in different clinical contexts. The amount of implementation barriers between the two guidelines was comparable. However, the identified barriers were clustered differently between the implementability dimensions.

It is expected that both guidelines will be updated or replaced by newer versions in the coming years. This study incentivizes a more extensive evaluation of intrinsic implementability and reformulation of recommendations with apparent barriers. Specific attention should go to the executability and decidability of individual recommendations. Patient populations, risk factors and threshold values used in RAMs are likely to benefit the most from more explicit formulations. Both guidelines can improve on this. In order to assure improved implementability characteristics in future guidelines, we recommend guideline developers to consider implementability assessments prior to dissemination. On a final note, we recognize that some of the underlying evidence used in guidelines might be insufficient to support straightforward risk assessments and clear cut trade-offs for VTEprophylaxis in the non-surgical patient population. This will be a challenge in developing guidelines with sufficient intrinsic implementability characteristics. The following is the supplementary data related to this article.

Download Word document (18KB)Help with docx files Table S1. The eGLIA instrument.

\section{Acknowledgements}

We wish to acknowledge J.F. de Groot from the Netherlands Institute for Health Services Research (NIVEL) for helping with interpretation of the results and L.M. Verweij from the Netherlands Institute for Health Services Research (NIVEL) for participating in the appraisal panel.

\section{Funding}

This work was supported by the Dutch Ministry of Healthcare Welfare and Sport.

\section{Competing interests}

The authors declare having no competing interests. 
Moesker, M., Damen, N., Volmeijer, E., Dreesens, D., Loos, E.M. de, Vink, R., Coppens, M., Krujp; M.J., Meijer, K., Langelaan, M., Bruijne, M.C. de, Wagner, C. Guidelines' risk assessment recommendations for venous thromboembolism prophylaxis: a comparison and implementability appraisal. Thrombosis Research: 2018, 168(8), 5-13

\section{REFERENCES}

[1] A.T. Cohen, G. Agnelli, F.A. Anderson, J.I. Arcelus, D. Bergqvist, J.G. Brecht, I.A. Greer, J.A. Heit, J.L. Hutchinson, A.K. Kakkar, D. Mottier, E. Oger, M.M. Samama, M. Spannagl, V.T.E.I.A.G.i. Europe, Venous thromboembolism (VTE) in Europe. The number of VTE events and associated morbidity and mortality, Thromb. Haemost. 98 (4) (2007) 756-764, http://dx.doi.org/10.1160/th07-03-0212.

[2] P.D. Stein, F. Matta, Epidemiology and incidence: the scope of the problem and risk factors for development of venous thromboembolism, Clin. Chest Med. 31 (4) (2010) 611628, http://dx.doi.org/10.1016/j.ccm.2010.07.001.

[3] S.Z. Goldhaber, V.F. Tapson, D.F.S. Committee, A prospective registry of 5,451 patients with ultrasound-confirmed deep vein thrombosis, Am. J. Cardiol. 93 (2) (2004) 259-262, http://dx.doi.org/10.1016/S0002-9149(03)01422-X.

[4] F.A. Anderson Jr., H.B. Wheeler, R.J. Goldberg, D.W. Hosmer, N.A. Patwardhan, B. Jovanovic, A. Forcier, J.E. Dalen, A population-based perspective of the hospital incidence and case-fatality rates of deep vein thrombosis and pulmonary embolism. The Worcester DVT Study, Arch. Intern. Med. 151 (5) (1991) 933-938.

[5] G.M. Bump, M. Dandu, S.R. Kaufman, K.G. Shojania, S.A. Flanders, How complete is the evidence for thromboembolism prophylaxis in general medicine patients? A meta-analysis of randomized controlled trials, J. Hosp. Med. 4 (5) (2009) 289-297, http://dx.doi.org/10.1002/jhm.450.

[6] F. Dentali, J.D. Douketis, M. Gianni, W. Lim, M.A. Crowther, Meta-analysis: anticoagulant prophylaxis to prevent symptomatic venous thromboembolism in hospitalized medical patients, Ann. Intern. Med. 146 (4) (2007) 278-288.

[7] L. Wein, S. Wein, S.J. Haas, J. Shaw, H. Krum, Pharmacological venous thromboembolism prophylaxis in hospitalized medical patients: a meta-analysis of randomized controlled trials, Arch. Intern. Med. 167 (14) (2007) 1476-1486, http://dx.doi.org/10.1001/archinte.167.14.1476.

[8] J.A. Heit, M.D. Silverstein, D.N. Mohr, T.M. Petterson, C.M. Lohse, W.M. O'Fallon, L.J. Melton 3rd, The epidemiology of venous thromboembolism in the community, Thromb. Haemost. 86 (1) (2001) 452-463.

[9] ACCP-NHLBI National Conference on Antithrombotic Therapy, American College of Chest Physicians and the National Heart, Lung and Blood Institute, Chest 89 (2 Suppl) (1986) 1S-106S.

[10] P.K. Han, C.N. Klabunde, N. Breen, G. Yuan, A. Grauman, W.W. Davis, S.H. Taplin, Multiple clinical practice guidelines for breast and cervical cancer screening: perceptions of US primary care physicians, Med. Care 49 (2) (2011) 139-148, http://dx.doi.org/10.1097/MLR.0b013e318202858e.

[11] M.C. Struijk-Mulder, H.B. Ettema, C.C. Verheyen, H.R. Buller, Comparing consensus guidelines on thromboprophylaxis in orthopedic surgery, J. Thromb. Haemost. 8 (4) (2010) 678-683, http://dx.doi.org/10.1111/j.1538-7836.2009.03728.x.

[12] K.L. Palmerola, M.E. D'Alton, C.O. Brock, A.M. Friedman, A comparison of recommendations for pharmacologic thromboembolism prophylaxis after caesarean delivery from three major guidelines, BJOG 123 (13) (2016) 2157-2162, http://dx.doi.org/10.1111/1471-0528.13706.

[13] P.F. Lachiewicz, Comparing and contrasting current guidelines for venous thromboembolism prophylaxis after total hip and total knee arthroplasty, Instr. Course Lect. 60 (2011) 301-307.

[14] A.T. Cohen, V.F. Tapson, J.F. Bergmann, S.Z. Goldhaber, A.K. Kakkar, B. Deslandes, W. Huang, M. Zayaruzny, L. Emery, F.A. Anderson Jr., E. Investigators, Venous thromboembolism risk and prophylaxis in the acute hospital care setting (ENDORSE study): a multinational cross-sectional study, Lancet 371 (9610) (2008) 387-394, http://dx.doi.org/10.1016/S0140-6736(08)60202-0.

[15] A.N. Amin, S. Stemkowski, J. Lin, G. Yang, Inpatient thromboprophylaxis use in U.S. hospitals: adherence to the seventh American College of Chest Physician's recommendations for at-risk medical and surgical patients, J. Hosp. Med. 4 (8) (2009) E15-E21, http://dx.doi.org/10.1002/jhm.526. 
Moesker, M., Damen, N., Volmeijer, E., Dreesens, D., Loos, E.M. de, Vink, R., Coppens, M., Krujp; M.J., Meijer, K., Langelaan, M., Bruijne, M.C. de, Wagner, C. Guidelines' risk assessment recommendations for venous thromboembolism prophylaxis: a comparison and implementability appraisal. Thrombosis Research: 2018, 168(8), 5-13

[16] G. Piazza, J. Fanikos, M. Zayaruzny, S.Z. Goldhaber, Venous thromboembolic events in hospitalised medical patients, Thromb. Haemost. 102 (3) (2009) 505-510, http://dx.doi.org/10.1160/TH09-03-0150.

[17] S.R. Kahn, A. Panju, W. Geerts, G.F. Pineo, L. Desjardins, A.G. Turpie, S. Glezer, L. Thabane, R.J. Sebaldt, C.s. investigators, Multicenter evaluation of the use of venous thromboembolism prophylaxis in acutely ill medical patients in Canada, Thromb. Res. 119 (2) (2007) 145-155, http://dx.doi.org/10.1016/j.thromres.2006.01.011 .

[18] R. Tooher, P. Middleton, C. Pham, R. Fitridge, S. Rowe, W. Babidge, G. Maddern, A systematic review of strategies to improve prophylaxis for venous thromboembolism in hospitals, Ann. Surg. 241 (3) (2005) 397-415, http://dx.doi.org/10.1097/01.sla.0000154120.96169.99 .

[19] R.N. Shiffman, J. Dixon, C. Brandt, A. Essaihi, A. Hsiao, G. Michel, R. O'Connell, The GuideLine Implementability Appraisal (GLIA): development of an instrument to identify obstacles to guideline implementation, BMC Med. Inform. Decis. Mak. 5 (2005) 23, http://dx.doi.org/10.1186/1472-6947-5-23.

[20] W.M. Tierney, J.M. Overhage, B.Y. Takesue, L.E. Harris, M.D. Murray, D.L. Vargo, C.J. McDonald, Computerizing guidelines to improve care and patient outcomes: the example of heart failure, J. Am. Med. Inform. Assoc. 2 (5) (1995) 316-322.

[21] D.A. Katz, Barriers between guidelines and improved patient care: an analysis of AHCPR's Unstable Angina Clinical Practice Guideline. Agency for Health Care Policy and Research, Health Serv. Res. 34 (1 Pt 2) (1999) 377-389.

[22] M. Kastner, J. Makarski, L. Hayden, L. Durocher, A. Chatterjee, M. Brouwers, O. Bhattacharyya, Making sense of complex data: a mapping process for analyzing findings of a realist review on guideline implementability, BMC Med. Res. Methodol. 13 (2013) 112, http://dx.doi.org/10.1186/1471-2288-13-112.

[23] S.R. Kahn, W. Lim, A.S. Dunn, M. Cushman, F. Dentali, E.A. Akl, D.J. Cook, A.A. Balekian, R.C. Klein, H. Le, S. Schulman, M.H. Murad, Prevention of VTE in nonsurgical patients: antithrombotic therapy and prevention of thrombosis, 9th ed: American College of Chest Physicians Evidence-Based Clinical Practice Guidelines, Chest 141 (2 Suppl) (2012) e195S-e226S, http://dx.doi.org/10.1378/chest.11-2296 .

[24] NICE Clinical Guideline 92: Venous Thromboembolism in Adults Admitted to Hospital: Reducing the Risk, www.nice.org.uk/guidance/cg92/resources/venousthromboembolismreducing-the-risk-for-patients-in-hospital-975745995973, (2010).

[25] Richtlijn Antitrombotisch Beleid, Integraal Kankercentrum Nederland; Kennisinstituut Medisch Specialisten, (2016).

[26] J. Stevanovic, L.A. de Jong, B.S. Kappelhoff, E.P. Dvortsin, M. Voorhaar, M.J. Postma, Dabigatran for the treatment and secondary prevention of venous thromboembolism; a cost-effectiveness analysis for the Netherlands, PLoS One 11 (10) (2016) e0163550, , http://dx.doi.org/10.1371/journal.pone.0163550.

[27] L.J. van Dijk, W.L. Nelen, T.M. D'Hooghe, G.A. Dunselman, R.P. Hermens, C. Bergh, K.G. Nygren, A.H. Simons, P. de Sutter, C. Marshall, J.S. Burgers, J.A. Kremer, The European Society of Human Reproduction and Embryology guideline for the diagnosis and treatment of endometriosis: an electronic guideline implementability appraisal, Implement. Sci. 6 (2011) 7, http://dx.doi.org/10.1186/1748-5908-6-7.

[28] S. Barbar, F. Noventa, V. Rossetto, A. Ferrari, B. Brandolin, M. Perlati, E. De Bon, D. Tormene, A. Pagnan, P. Prandoni, A risk assessment model for the identification of hospitalized medical patients at risk for venous thromboembolism: the Padua Prediction Score, J. Thromb. Haemost. 8 (11) (2010) 2450-2457, http://dx.doi.org/10.1111/j.15387836.2010.04044.x.

[29] H. Decousus, V.F. Tapson, J.F. Bergmann, B.H. Chong, J.B. Froehlich, A.K. Kakkar, G.J. Merli, M. Monreal, M. Nakamura, R. Pavanello, M. Pini, F. Piovella, F.A. Spencer, A.C. Spyropoulos, A.G. Turpie, R.B. Zotz, G. Fitzgerald, F.A. Anderson, I. Investigators, Factors at admission associated with bleeding risk in medical patients: findings from the IMPROVE investigators, Chest 139 (1) (2011) 69-79, http://dx.doi.org/10.1378/chest.09-3081.

[30] A.K. Stuck, D. Spirk, J. Schaudt, N. Kucher, Risk assessment models for venous thromboembolism in acutely ill medical patients. A systematic review, Thromb. Haemost. 117 (4) (2017) 801-808, http://dx.doi.org/10.1160/TH16-08-0631. 
Moesker, M., Damen, N., Volmeijer, E., Dreesens, D., Loos, E.M. de, Vink, R., Coppens, M., Krujp? M.J., Meijer, K., Langelaan, M., Bruijne, M.C. de, Wagner, C. Guidelines' risk assessment recommendations for venous thromboembolism prophylaxis: a comparison and implementability appraisal. Thrombosis Research: 2018, 168(8), 5-13

[31] M.M. Samama, S. Combe, J. Conard, M.H. Horellou, Risk assessment models for thromboprophylaxis of medical patients, Thromb. Res. 129 (2) (2012) 127-132, http://dx.doi.org/10.1016/j.thromres.2011.09.025.

[32] M.T. Greene, A.C. Spyropoulos, V. Chopra, P.J. Grant, S. Kaatz, S.J. Bernstein, S.A. Flanders, Validation of risk assessment models of venous thromboembolism in hospitalized medical patients, Am. J. Med. 129 (9) (2016) 1001 e9-1001 e18 https://doi.org/10.1016/j.amjmed.2016.03.031.

[33] D.J. Rosenberg, A. Press, J. Fishbein, M. Lesser, L. McCullagh, T. McGinn, A.C. Spyropoulos, External validation of the IMPROVE Bleeding Risk Assessment Model in medical patients, Thromb. Haemost. 116 (3) (2016) 530-536, http://dx.doi.org/10.1160/TH16-01-0003 .

[34] M. La Regina, F. Orlandini, F. Marchini, A. Marinaro, R. Bonacci, P. Bonanni, F. Corsini, A.M. Ceraudo, E. Pacetti, L. Scuotri, D. Costabile, F. Dentali, Combined assessment of thrombotic and haemorrhagic risk in acute medical patients, Thromb. Haemost. 115 (2) (2016) 392-398, http://dx.doi.org/10.1160/TH14-12-1050.

[35] A. Limpus, W. Chaboyer, E. McDonald, L. Thalib, Mechanical thromboprophylaxis in critically ill patients: a systematic review and meta-analysis, Am. J. Crit. Care 15 (4) (2006) 402-410 (quiz/discussion, 411-2).

[36] V.F. Tapson, H. Decousus, M. Pini, B.H. Chong, J.B. Froehlich, M. Monreal, A.C. Spyropoulos, G.J. Merli, R.B. Zotz, J.F. Bergmann, R. Pavanello, A.G. Turpie, M. Nakamura, F. Piovella, A.K. Kakkar, F.A. Spencer, G. Fitzgerald, F.A. Anderson Jr., I. Investigators, Venous thromboembolism prophylaxis in acutely ill hospitalized medical patients: findings from the International Medical Prevention Registry on Venous Thromboembolism, Chest 132 (3) (2007) 936-945, http://dx.doi.org/10.1378/chest.062993.

[37] Standards for Developing Trustworthy Clinical Practice Guidelines, Institue of Medicine, 2011.

[38] A.R. Gagliardi, M.C. Brouwers, V.A. Palda, L. Lemieux-Charles, J.M. Grimshaw, How can we improve guideline use? A conceptual framework of implementability, Implement. Sci. 6 (2011) 26, http://dx.doi.org/10.1186/1748-5908-6-26.

[39] G. Maynard, J. Stein, Designing and implementing effective venous thromboembolism prevention protocols: lessons from collaborative efforts, J. Thromb. Thrombolysis 29 (2) (2010) 159-166, http://dx.doi.org/10.1007/s11239-009-0405-4.

[40] H. Taha, S.J. Raji, S. Ellahham, N. Bashir, M. Al Hanaee, H. Boharoon, M. AlFalahi, Improving venous thromboembolism risk assessment compliance using the electronic tool in admitted medical patients, BMJ Qual. Improv. Rep. 4 (1) (2015), http://dx.doi.org/10.1136/bmjquality.u209593.w3965.

[41] M.C. Brouwers, M.E. Kho, G.P. Browman, J.S. Burgers, F. Cluzeau, G. Feder, B. Fervers, I.D. Graham, J. Grimshaw, S.E. Hanna, P. Littlejohns, J. Makarski, L.

Zitzelsberger, A.N.S. Consortium, AGREE II: advancing guideline development, reporting and evaluation in health care, CMAJ 182 (18) (2010) E839-E842, http://dx.doi.org/10.1503/cmaj.090449 .

[42] M.C. Brouwers, M.E. Kho, G.P. Browman, J.S. Burgers, F. Cluzeau, G. Feder, B. Fervers, I.D. Graham, S.E. Hanna, J. Makarski, A.N.S. Consortium, Development of the AGREE II, part 1: performance, usefulness and areas for improvement, CMAJ 182 (10) (2010) 1045-1052, http://dx.doi.org/10.1503/cmaj.091714.

[43] M.C. Brouwers, J. Makarski, M. Kastner, L. Hayden, O. Bhattacharyya, G.- M.R. Team, The Guideline Implementability Decision Excellence Model (GUIDE-M): a mixed methods approach to create an international resource to advance the practice guideline field, Implement. Sci. 10 (2015) 36, http://dx.doi.org/10.1186/s13012-015-0225-1 .

[44] M. Goldin, J. Cohen, A. Makhnevich, C. Mulvany, M. Akerman, L. Sinvani, Patterns and outcomes of prescribing venous thromboembolism prophylaxis in hospitalized older adults: a retrospective cohort study, J. Thromb. Thrombolysis 45 (3) (2018) 369-376, http://dx.doi.org/10.1007/s11239-018-1611-8.

[45] J. Suh, A. Desai, A. Desai, J.D. Cruz, A. Mariampillai, A. Hindenburg, Adherence to thromboprophylaxis guidelines in elderly patients with hospital acquired venous thromboembolism: a case control study, J. Thromb. Thrombolysis 43 (2) (2017) 172-178, http://dx.doi.org/10.1007/s11239-016-1432-6. 
Moesker, M., Damen, N., Volmeijer, E., Dreesens, D., Loos, E.M. de, Vink, R., Coppens, M., Krujp, M.J., Meijer, K., Langelaan, M., Bruijne, M.C. de, Wagner, C. Guidelines' risk assessment recommendations for venous thromboembolism prophylaxis: a comparison and implementability appraisal. Thrombosis Research: 2018, 168(8), 5-13

[46] F.M. Al-Hameed, H.M. Al-Dorzi, A.I. Qadhi, A. Shaker, F.H. Al-Gahtani, F.F. Al- Jassir, G.F. Zahir, T.S. Al-Khuwaitir, M.H. Addar, M.S. Al-Hajjaj, M.A. Abdelaal, E.Y. Aboelnazar, Thromboprophylaxis and mortality among patients who developed venous thromboembolism in seven major hospitals in Saudi Arabia, Ann. Thorac. Med. 12 (4) (2017) 282-289, http://dx.doi.org/10.4103/atm.ATM_101_17.

\section{TABLES}

Table 1. Recommendations appraised with eGLIA for each guideline. Guideline Recommendations appraised with eGLIA

\begin{tabular}{|c|c|}
\hline \multirow{6}{*}{ ACCP } & $\begin{array}{l}\text { 2.3. For acutely ill hospitalized medical patients at increased risk of thrombosis (Table 2), we recommend } \\
\text { anticoagulant thromboprophylaxis with LMWH, LDUH bid, LDUH tid or fondaparinux }\end{array}$ \\
\hline & $\begin{array}{l}\text { 2.4. For acutely ill hospitalized medical patients at low risk of thrombosis (Table 2), we recommend } \\
\text { against the use of pharmacologic prophylaxis or mechanical prophylaxis }\end{array}$ \\
\hline & $\begin{array}{l}\text { 2.7.1. For acutely ill hospitalized medical patients who are bleeding or at a high risk for bleeding (Table } \\
\text { 3), we recommend against anticoagulant thromboprophylaxis }\end{array}$ \\
\hline & $\begin{array}{l}\text { 2.7.2. For acutely ill hospitalized medical patients at increased risk of thrombosis who are bleeding or at } \\
\text { high risk for major bleeding, we suggest the optimal use of mechanical thromboprophylaxis with } \\
\text { graduated compression stockings (GCS) or intermittent pneumatic compression (IPC), rather than no } \\
\text { mechanical thromboprophylaxis. When bleeding risk decreases, and if VTE-risk persists, we suggest } \\
\text { that pharmacologic thromboprophylaxis be substituted for mechanical thromboprophylaxis }\end{array}$ \\
\hline & 3.4.3. For critically ill patients, we suggest using LMWH or LDUH thromboprophylaxis over no prophylaxis \\
\hline & $\begin{array}{l}\text { 3.4.4. For critically ill patients who are bleeding, or are at high risk for major bleeding (Table 3), we } \\
\text { suggest mechanical thromboprophylaxis with GCS or IPC until the bleeding risk decreases, rather than } \\
\text { no mechanical thromboprophylaxis. When bleeding risk decreases, we suggest that pharmacologic } \\
\text { thromboprophylaxis be substituted for mechanical thromboprophylaxis }\end{array}$ \\
\hline \multirow{9}{*}{ NICE } & $\begin{array}{l}\text { 1.1.2. Regard medical patients as being at increased risk of VTE if they: } \\
\text { - have had or are expected to have significantly reduced mobility for } 3 \text { days or more } \\
\text { or } \\
\text { - are expected to have on-going reduced mobility relative to their normal state and have one or more of } \\
\text { the risk factors shown in box } 1\end{array}$ \\
\hline & $\begin{array}{l}\text { 1.1.4. Assess all patients for risk of bleeding before offering pharmacological VTE-prophylaxis. Do not } \\
\text { offer pharmacological VTE-prophylaxis to patients with any of the risk factors for bleeding shown in box } \\
2 \text {, unless the risk of VTE outweighs the risk of bleeding }\end{array}$ \\
\hline & $\begin{array}{l}\text { 1.4.1. Offer pharmacological VTE-prophylaxis to general medical patients assessed to be at increased } \\
\text { risk of VTE. Choose any one of: } \\
\text { - fondaparinux sodium } \\
\text { - low molecular weight heparin (LMWH) } \\
\text { - unfractionated heparin (UFH) (for patients with severe renal impairment or established renal failure) }\end{array}$ \\
\hline & $\begin{array}{l}\text { 1.4.6. Offer pharmacological VTE-prophylaxis to patients with cancer who are assessed to be at } \\
\text { increased risk of VTE (see Section 1.1). Choose any one of: } \\
\text { - fondaparinux sodium } \\
\text { - LMWH } \\
\text { - UFH (for patients with severe renal impairment or established renal failure) } \\
\text { Start pharmacological VTE-prophylaxis as soon as possible after risk assessment has been completed. } \\
\text { Continue until the patient is no longer at increased risk of VTE. }\end{array}$ \\
\hline & $\begin{array}{l}\text { 1.4.7. Do not routinely offer pharmacological or mechanical VTE-prophylaxis to patients with cancer } \\
\text { having oncological treatment who are ambulant }\end{array}$ \\
\hline & $\begin{array}{l}\text { 1.4.8. Do not routinely offer pharmacological or mechanical VTE-prophylaxis to patients with central } \\
\text { venous catheters who are ambulant }\end{array}$ \\
\hline & $\begin{array}{l}\text { 1.4.9. Consider offering pharmacological VTE-prophylaxis with LMWH (or UFH for patients with severe } \\
\text { renal impairment or established renal failure) to patients with central venous catheters who are at } \\
\text { increased risk of VTE (see Section 1.1) }\end{array}$ \\
\hline & $\begin{array}{l}\text { 1.4.13. Consider offering mechanical VTE-prophylaxis to medical patients in whom pharmacological VTE- } \\
\text { prophylaxis is contraindicated. Choose any one of: } \\
\text { - anti-embolism stockings (thigh or knee length) } \\
\text { - foot impulse devices } \\
\text { - intermittent pneumatic compression devices (thigh or knee length) }\end{array}$ \\
\hline & $\begin{array}{l}\text { 1.6.8. Offer VTE-prophylaxis to patients admitted to the critical care unit according to the reason for } \\
\text { admission, taking into account: } \\
\text { - any planned interventions } \\
\text { - the use of other therapies that may increase the risk of complications }\end{array}$ \\
\hline
\end{tabular}

LMWH low molecular weight heparin; LDUH low dose unfractionated heparin; GCS graduated compression stockings; IPC intermittent pneumatic compression; VTE venous thromboembolism. 
Moesker, M., Damen, N., Volmeijer, E., Dreesens, D., Loos, E.M. de, Vink, R., Coppens, M., Krujp, M.J., Meijer, K., Langelaan, M., Bruijne, M.C. de, Wagner, C. Guidelines' risk assessment recommendations for venous thromboembolism prophylaxis: a comparison and implementability appraisal. Thrombosis Research: 2018, 168(8), 5-13

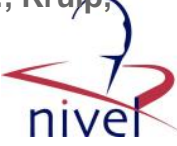

Table 2. Recommendation specifications for the VTE-risk assessment components per guideline.

\begin{tabular}{|c|c|c|}
\hline \multirow{2}{*}{$\begin{array}{l}\text { Risk assessment } \\
\text { component }\end{array}$} & \multicolumn{2}{|l|}{ Guideline } \\
\hline & ACCP & NICE \\
\hline \multirow{21}{*}{$\begin{array}{l}\text { Risk factors included } \\
\text { in the VTE-risk } \\
\text { assessment }\end{array}$} & -Active cancer & -Active cancer or cancer treatment \\
\hline & $\begin{array}{l}\text {-Previous VTE (with the exclusion of } \\
\text { superficial vein thrombosis) }\end{array}$ & -Personal history of VTE \\
\hline & & -First degree relative with a history of VTE \\
\hline & $\begin{array}{l}\text {-Already known thrombophilic } \\
\text { condition }\end{array}$ & -Known thrombophilia's \\
\hline & $\begin{array}{l}\text {-Recent ( } \leq 1 \text { month) trauma and/or } \\
\text { surgery }\end{array}$ & \\
\hline & -Elderly age ( $\geq 70$ years) & -Age over 60 years \\
\hline & $\begin{array}{l}\text {-Heart failure } \\
\text {-Acute myocardial infarction }\end{array}$ & -Heart disease \\
\hline & -Respiratory failure & -Respiratory pathologies \\
\hline & -Acute infection & -Acute infectious diseases \\
\hline & -Acute rheumatologic disorder & \\
\hline & -Ischemic stroke & \\
\hline & -Obesity (BMI $\geq 30)$ & -Obesity (BMI $\geq 30)$ \\
\hline & \multirow{2}{*}{-Ongoing hormonal treatment } & -Use of hormone replacement therapy \\
\hline & & -Use of oestrogen-containing contraceptives \\
\hline & -Patients admitted to ICU/CCU & -Critical care admission \\
\hline & & -Inflammatory conditions \\
\hline & & -Metabolic pathologies \\
\hline & & -Endocrine pathologies \\
\hline & & -Dehydration \\
\hline & & -Varicose veins with phlebitis \\
\hline & $\begin{array}{l}\text {-Reduced mobility (anticipated bed } \\
\text { rest with bathroom privileges either } \\
\text { because of patient's limitations or } \\
\text { on physician's order for at least } \\
3 \text { days) }\end{array}$ & $\begin{array}{l}\text {-A significantly reduced mobility (bedbound, unable to } \\
\text { walk unaided or likely to spend a substantial } \\
\text { proportion of the day in bed or in a chair) for } \geq 3 \text { days } \\
\text {-On-going reduced mobility relative to normal state }\end{array}$ \\
\hline \multirow{19}{*}{$\begin{array}{l}\text { Risk factors included } \\
\text { in the bleeding risk } \\
\text { assessment }\end{array}$} & -Active gastroduodenal ulcer & \\
\hline & -Active bleeding & -Active bleeding \\
\hline & $\begin{array}{l}\text {-Bleeding in } 3 \text { months before } \\
\text { admission }\end{array}$ & \\
\hline & -Platelet count $<50 \times 10^{9} / \mathrm{L}$ & -Thrombocytopenia (platelets $<75 \times 10^{y} / \mathrm{L}$ ) \\
\hline & - Age $\geq 85$ years & \\
\hline & -Hepatic failure (INR > 1.5) & \\
\hline & $\begin{array}{l}\text {-Severe renal failure (GFR } \\
<30 \mathrm{~mL} / \mathrm{min} / \mathrm{m} 2 \text { ) } \\
\end{array}$ & \\
\hline & -ICU or CCU admission & \\
\hline & -Central venous catheter & \\
\hline & -Rheumatic disease & \\
\hline & -Current cancer & \\
\hline & -Male sex & \\
\hline & & $\begin{array}{l}\text {-Acquired bleeding disorders (such as acute liver } \\
\text { failure) }\end{array}$ \\
\hline & & $\begin{array}{l}\text {-Concurrent use of anticoagulants known to increase } \\
\text { the risk of bleeding (such as warfarin with INR } \\
\text { higher than 2) }\end{array}$ \\
\hline & & $\begin{array}{l}\text {-Lumbar puncture/epidural/spinal anaesthesia } \\
\text { expected within the next } 12 \mathrm{~h}\end{array}$ \\
\hline & & $\begin{array}{l}\text {-Lumbar puncture/epidural/spinal anaesthesia within } \\
\text { the previous } 4 \mathrm{~h}\end{array}$ \\
\hline & & -Acute stroke \\
\hline & & $\begin{array}{l}\text {-Uncontrolled systolic hypertension (230/120mmHG or } \\
\text { higher) }\end{array}$ \\
\hline & & $\begin{array}{c}\text {-Untreated inherited bleeding disorders (such as } \\
\text { haemophilia and von Willebrand's disease) }\end{array}$ \\
\hline
\end{tabular}


Moesker, M., Damen, N., Volmeijer, E., Dreesens, D., Loos, E.M. de, Vink, R., Coppens, M., Krujp M.J., Meijer, K., Langelaan, M., Bruijne, M.C. de, Wagner, C. Guidelines' risk assessment recommendations for venous thromboembolism prophylaxis: a comparison and implementability appraisal. Thrombosis Research: 2018, 168(8), 5-13

\begin{tabular}{|c|c|c|}
\hline \multirow{2}{*}{$\begin{array}{c}\text { Risk assessment } \\
\text { component }\end{array}$} & \multicolumn{2}{|l|}{ Guideline } \\
\hline & ACCP & NICE \\
\hline \multirow{5}{*}{$\begin{array}{l}\text { Criteria for indicating } \\
\text { pharmacologic VTE- } \\
\text { prophylaxis }\end{array}$} & Patients with PADUA score $\geq 4$ & $\begin{array}{l}\text { Patients with or expected to have a significantly } \\
\text { reduced mobility for } \geq 3 \text { days }\end{array}$ \\
\hline & Patients admitted to ICU/CCU & $\begin{array}{l}\text { Patients expected to have on-going reduced mobility } \\
\text { relative to their normal state and have one or more } \\
\text { of the above VTE-risk factors }\end{array}$ \\
\hline & & $\begin{array}{l}\text { Patients with a cancer and have one or more of the } \\
\text { above VTE-risk factors }\end{array}$ \\
\hline & & $\begin{array}{l}\text { Patients with a central venous catheter and having } \\
\text { one or more of the above VTE-risk factors }\end{array}$ \\
\hline & & $\begin{array}{l}\text { Patients admitted to the critical care unit according to } \\
\text { the reason for admission and taking into account: } \\
\text { any planned interventions and the use of other } \\
\text { therapies that may increase the risk of complications }\end{array}$ \\
\hline \multirow{5}{*}{$\begin{array}{l}\text { Criteria for contra- } \\
\text { indicating } \\
\text { pharmacologic VTE- } \\
\text { prophylaxis }\end{array}$} & Patients who are bleeding & $\begin{array}{l}\text { Patients with any of the risk factors for bleeding, } \\
\text { unless the risk of VTE outweighs the risk of bleeding }\end{array}$ \\
\hline & $\begin{array}{l}\text { Patients with more than one of the } \\
\text { above mentioned risk factors }\end{array}$ & \\
\hline & $\begin{array}{l}\text { Patients with active gastroduodenal } \\
\text { ulcer }\end{array}$ & \\
\hline & $\begin{array}{l}\text { Patients with bleeding in } 3 \text { months } \\
\text { before admission }\end{array}$ & \\
\hline & $\begin{array}{l}\text { Patients with a platelet count } \\
<50 \times 10^{9} / \mathrm{L}\end{array}$ & \\
\hline $\begin{array}{l}\text { Criteria for indicating } \\
\text { mechanical VTE- } \\
\text { prophylaxis }\end{array}$ & $\begin{array}{l}\text { Patients classified as having an } \\
\text { increased risk of VTE and are } \\
\text { bleeding or classified as being at } \\
\text { high risk for bleeding }\end{array}$ & $\begin{array}{l}\text { Patients for whom pharmacologic prophylaxis is } \\
\text { contra-indicated }\end{array}$ \\
\hline
\end{tabular}

VTE venous thromboembolism; BMI body-mass index; ICU intensive care unit; CCU cardiac care unit; INR international normalized ratio. 
Moesker, M., Damen, N., Volmeijer, E., Dreesens, D., Loos, E.M. de, Vink, R., Coppens, M., Krujp, M.J., Meijer, K., Langelaan, M., Bruijne, M.C. de, Wagner, C. Guidelines' risk assessment recommendations for venous thromboembolism prophylaxis: a comparison and implementability appraisal. Thrombosis Research: 2018, 168(8), 5-13

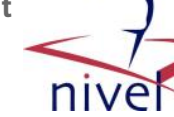

Fig. 1. Final eGLIA appraisal results for the ACCP and NICE guideline.
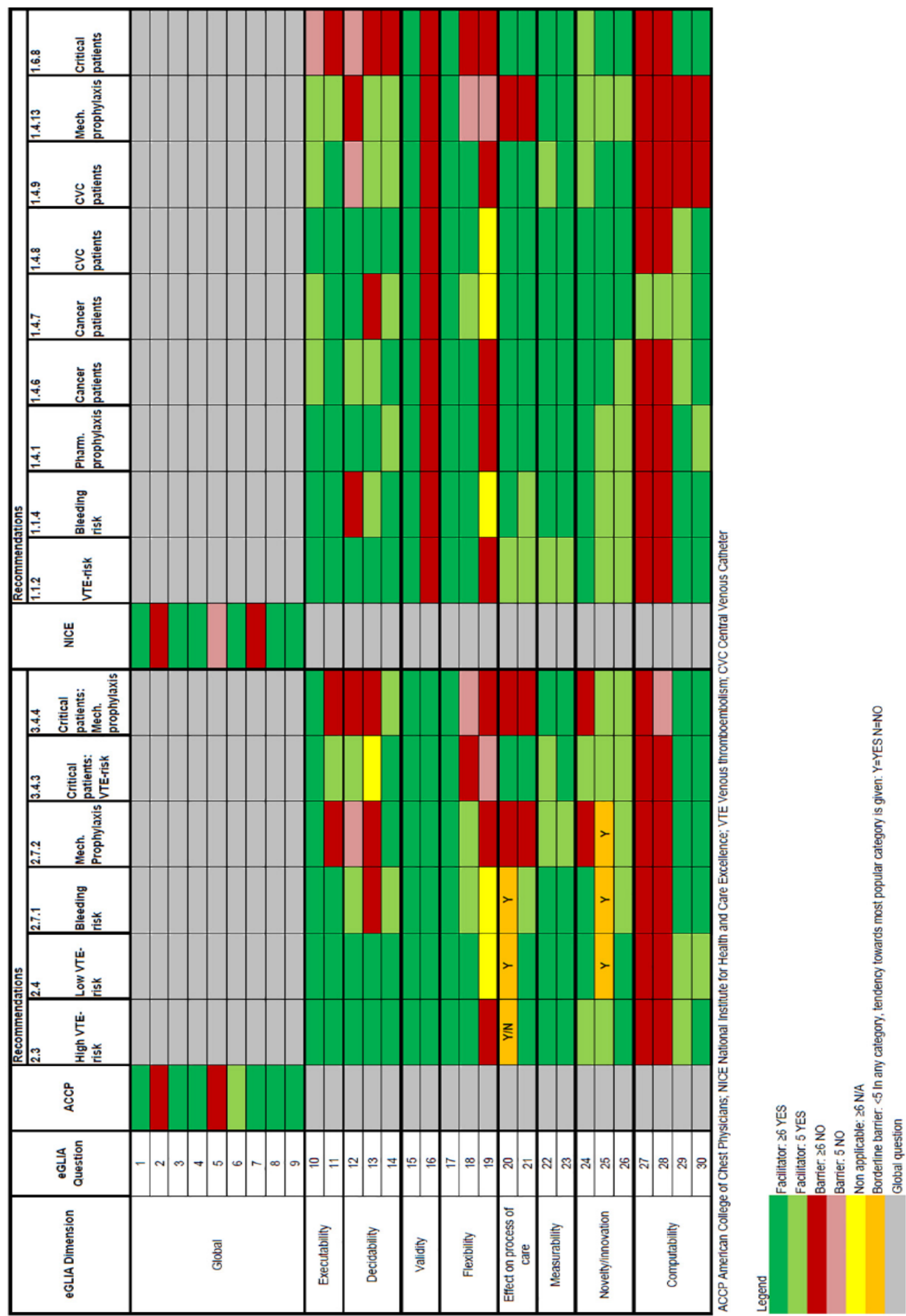


\section{Supporting information}

Table S1 The eGLIA instrument

eGLIA Dimension

\begin{tabular}{|c|c|c|}
\hline Dime & & stion \\
\hline \multirow{9}{*}{ Global } & 1 & Does the guideline clearly define the target patient population? \\
\hline & 2 & Does the guideline clearly define its intended audience (i.e., types of providers)? \\
\hline & 3 & Are the settings in which the guideline is to be used clearly described? \\
\hline & 4 & $\begin{array}{l}\text { Do the organization(s) and author(s) who developed the guideline have credibility with the intended } \\
\text { audience of the guideline? }\end{array}$ \\
\hline & 5 & $\begin{array}{l}\text { Does the guideline suggest strategies for implementation or tools for application e.g., a summary } \\
\text { document, a quick reference guide, educational tools, patients' leaflets, online resources or computer } \\
\text { software? }\end{array}$ \\
\hline & 6 & Is it clear in what sequence the recommendations should be applied? \\
\hline & 7 & $\begin{array}{l}\text { Is the guideline internally consistent, i.e., without contradictions between recommendations or between } \\
\text { text recommendations and flowcharts, summaries, patient education materials, etc.? }\end{array}$ \\
\hline & 8 & Are all recommendations easily identifiable, e.g., summarized in a box, bold text, underlined, etc.? \\
\hline & 9 & $\begin{array}{l}\text { Are all recommendations (and their discussions) concise? (Longwinded explanations impair } \\
\text { implementability.) }\end{array}$ \\
\hline Executability & 11 & $\begin{array}{l}\text { Is sufficient detail provided or referenced (about how to do it) to allow the intended audience to perform } \\
\text { the recommended action. }\end{array}$ \\
\hline \multirow{3}{*}{ Decidability } & 12 & $\begin{array}{l}\text { Would the guideline's intended audience consistently determine whether each condition in the } \\
\text { recommendation has been satisfied? That is, is each and every condition described clearly enough so that } \\
\text { reasonable practitioners would agree when the recommendation should be applied? }\end{array}$ \\
\hline & 13 & Are all reasonable combinations of conditions addressed? \\
\hline & 14 & $\begin{array}{l}\text { If this recommendation contains more than one condition, is the logical relationship (ANDs and ORs) } \\
\text { between conditions clear? }\end{array}$ \\
\hline \multirow{2}{*}{ Validity } & 15 & Is the justification for the recommendation stated explicitly? \\
\hline & 16 & Is the quality of evidence that supports each recommendation stated explicitly? \\
\hline
\end{tabular}




\begin{tabular}{|c|c|c|}
\hline \multirow{3}{*}{ Flexibility } & 17 & $\begin{array}{l}\text { Is the strength of each recommendation stated explicitly? Note: Strength of recommendation reflects } \\
\text { anticipated level of adherence and is different from quality of evidence (question 16). Potential statements } \\
\text { to satisfy this criterion might include 'Strong recommendation', 'Standard', 'Clinical option', etc. }\end{array}$ \\
\hline & 18 & $\begin{array}{l}\text { Does the recommendation specify patient characteristics (such as coincident drug therapy and common co- } \\
\text { morbid conditions) that require or permit individualization? }\end{array}$ \\
\hline & 19 & $\begin{array}{l}\text { Does the recommendation specify practice characteristics (such as location and availability of support } \\
\text { services) that require or permit modification? }\end{array}$ \\
\hline \multirow[b]{2}{*}{$\begin{array}{l}\text { Effect on process } \\
\text { of care }\end{array}$} & 20 & Can the recommendation be carried out without substantial disruption in current workflow? \\
\hline & 21 & $\begin{array}{l}\text { Can the recommendation be pilot tested without substantial resource commitment? For example, buying } \\
\text { and installing expensive equipment to comply with a recommendation is not easily reversible. }\end{array}$ \\
\hline \multirow{2}{*}{ Measurability } & 22 & $\begin{array}{l}\text { Can adherence to this recommendation be measured? Measurement of adherence requires attention to } \\
\text { both the actions performed and the circumstances under which the actions are performed. }\end{array}$ \\
\hline & 23 & $\begin{array}{l}\text { Can outcomes of this recommendation be measured? Outcomes include such things as changes in health } \\
\text { status, mortality, costs, and satisfaction. }\end{array}$ \\
\hline \multirow{2}{*}{ Novelty/innovation } & 24 & $\begin{array}{l}\text { Can the recommendation be performed by the guideline's intended users without acquisition of new } \\
\text { knowledge or skills? }\end{array}$ \\
\hline & 26 & $\begin{array}{l}\text { Is the recommendation consistent with patient expectations? In general, patients expect their concerns to } \\
\text { be taken seriously, benefits of interventions to exceed risks, and adverse outcomes to fall within an } \\
\text { acceptable range. }\end{array}$ \\
\hline \multirow{4}{*}{ Computability } & 27 & $\begin{array}{l}\text { Are all patient data needed for this recommendation available electronically in the system in which it is to } \\
\text { be implemented? }\end{array}$ \\
\hline & 28 & $\begin{array}{l}\text { Is each condition of the recommendation defined at a level of specificity suitable for electronic } \\
\text { implementation? }\end{array}$ \\
\hline & 29 & Is each recommended action defined at a level of specificity suitable for electronic implementation? \\
\hline & 30 & $\begin{array}{l}\text { Is it clear by what means a recommended action can be executed in an electronic setting, e.g., creating a } \\
\text { prescription, medical order, or referral, creating an electronic mail notification, or displaying a dialog box? }\end{array}$ \\
\hline
\end{tabular}

